\title{
Entrevista a Jomo Kwame Sundaram
}

5 de marzo de 2021

Revista Derechos en Acción ISSN 2525-1678/ e-ISSN 2525-1686 Año 6/No 18, Verano 2020-2021 (21 diciembre a 20 marzo), 898-904 DOI: https://doi.org/10.24215/25251678e506

Jomo Kwame Sundaram es asesor principal del Instituto de Investigación Khazanah, miembro de la Academia de Ciencias de Malasia, profesor emérito de la Universidad de Malaya y miembro visitante de la Iniciativa para el Diálogo Político de la Universidad de Columbia. Fue fundador y presidente de International Development Economics Associates (IDEAs), Subsecretario General de

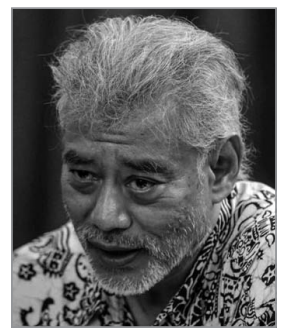
Desarrollo Económico de la ONU (2005-2012) y Subdirector General de la Organización de las Naciones Unidas para la Agricultura y la Alimentación (FAO) (2012-2015). Recibió el Premio Wassily Leontief 2007 por el avance de las fronteras del pensamiento económico.

- ¿Por qué sostiene que, en este contexto, las reestructuraciones de la deuda son una "distracción de la deuda"?

-En el contexto de contagios de COVID-19, muchos gobiernos del mundo actuaron solo en pos de contener el contagio de un virus que se propagaba por las sociedades, a diferencia de otros gobiernos, principalmente en Asia Oriental. Estos actuaron rápida e integralmente para contener la epidemia mediante testeos masivos, rastreo, aislamiento y tratamiento de las personas sospechosas de estar infectadas. De este modo, a medida que la epidemia se propagaba a nivel nacional, muchos de los 
gobiernos impusieron cuarentenas "Quedate en casa" junto con un paquete de medidas para controlar los contagios. Esas medidas interrumpieron buena parte de la actividad económica en un esfuerzo tardío por limitar los contagios, particularmente en las actividades que requerían cercanía física entre los y las empleadas, con la clientela o, por ejemplo, los servicios de hotelería, colectivos, trenes y aviones. También interrumpieron las cadenas de suministro de productos que perdieron cercanía con la creciente popularidad de las cadenas de suministro o valor a lo largo de las últimas décadas, de la mano de la deslocalización y la transnacionalización de los procesos productivos.

La desaceleración económica resultante se produjo justo después de una década de tenue recuperación económica tras la crisis financiera mundial de 2008-2009 y la Gran Recesión subsiguiente. Si no se lleva a cabo una iniciativa efectiva para recuperar liquidez y aumentar la demanda agregada, el temor a que las recesiones se conviertan en depresiones tiene asidero.

Si bien las medidas de apoyo monetarias son indudablemente útiles, ante estas amenazas lo que se necesita urgentemente son grandes esfuerzos fiscales expansivos. Con la lenta y constante acumulación de deuda soberana de la última década, debida en gran parte a la disminución de la recaudación de ingresos, los gobiernos siguieron centrándose en la carga acumulada de esos préstamos y se vieron restringidos a la hora de responder a la necesidad de una acción urgente y adecuada.

\section{-Si los gobiernos tuvieran que destinar fondos a "lo que es importante en la vida”, ¿cuáles serían las prioridades? ¿Los derechos humanos ofrecen una guía para eso? ¿Se relacio- nan con la recuperación económica?}

—En vez de discutir estas cuestiones en abstracto, tomemos en consideración la situación actual. Hay una falsa disyuntiva en juego entre salud y economía. Una respuesta para ambas opciones es contener de manera efectiva el contagio, ya que así se salvan vidas y se evita la necesidad de cuarentenas del tipo 
"Quedate en casa", permitiendo que las actividades económicas vuelvan a ponerse en marcha. Un esfuerzo fiscal sostenido es particularmente crucial para garantizar que las recesiones no se conviertan en depresiones. Esto podría requerir que los gobiernos tomen más deuda que nunca y que deban garantizar que el gasto adicional esté destinado de manera sensata, justa y efectiva a proveer alivio y promover la recuperación. Luego del acelerado desarrollo de vacunas, el desafío ahora radica en garantizar que sean distribuidas de manera rápida, justa y accesible, considerando las necesidades por encima de las capacidades de pago. Ante el debilitamiento del multilateralismo, los grandes poderes han reafirmado sus intereses, dando lugar a un imperialismo de las vacunas, tal y como parece estar ocurriendo.

El discurso contemporáneo de los derechos humanos está arraigado en supuestos neoliberales, especialmente los de un liberalismo personalista que funciona en una economía de mercado. Aunque por lo general se enmarca en el Estado de derecho, no suele ofrecer medios universalmente aceptados para eludir demandas contrarias, como las de derecho de propiedad e incluso de propiedad intelectual.

Por ejemplo, los y las defensoras de los derechos humanos han estado notablemente ausentes a la hora de abogar por la exención de los derechos de propiedad intelectual sobre las vacunas. Los gobiernos de países ricos se opusieron a este pedido de exención dirigido a la Organización Mundial del Comercio (OMC), y lo bloquearon en defensa de la propiedad intelectual y en búsqueda de un "nacionalismo de las vacunas". $\mathrm{Y}$ es así como las compañías a cargo de las vacunas, que ya recibieron miles de millones de financiamiento público, siguen negándose a revelar sus hallazgos en materia de investigación. Poner esa información a disposición puede no solo acelerar el desarrollo de las vacunas y sus mejoras, sino que la exención es sumamente necesaria para aumentar de manera significativa la producción y suministro de vacunas genéricas. Esto permitiría llevar adelante vacunaciones masivas rápidas, eficaces, 
accesibles y equitativas, a fin de superar más velozmente la pandemia. A cambio, mitigaría la inmensa perturbación que esta causó, reduciendo la pérdida de vidas y de actividad económica. Cuando se pusieron en debate los derechos en la OMC, la referencia de los países ricos - campeones de los derechos humanos - aludieron, en cambio, a los derechos de la propiedad intelectual, incluso en materia de salud.

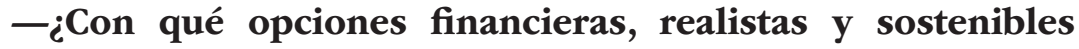 cuentan los países de ingresos medios como la Argentina para aumentar su espacio fiscal?}

-La experiencia financiera reciente de la Argentina, en las últimas tres décadas, es realmente bastante excepcional entre los países en desarrollo, hay otras personas en mejor posición que yo para discutir la situación del país. La mayoría del resto de países en desarrollo están mejor posicionados para pedir préstamos que la Argentina. No obstante, parece que el gobierno actual lo ha hecho bastante bien en unir la nación, o al menos las principales tendencias políticas, primero para gestionar la pandemia de COVID-19, y luego para abordar el problema de la excesiva deuda soberana. Sin embargo, aún no está claro hasta qué punto lograrán sortear las limitaciones al gasto público que el gobierno precisa hacer urgentemente para enfrentar la crisis. Muchos países de ingresos medios ya están endeudados en diferente medida. La comunidad financiera y los medios de comunicación empresariales han advertido con frecuencia que sus calificaciones crediticias se verán afectadas negativamente si piden más préstamos. Un conjunto de "halcones de la deuda" a lo largo del espectro político les han aconsejado a los países endeudados que usen sus escasos recursos fiscales para pagar sus deudas, en vez de hacer un gasto más juicioso y destinarlos a paliar la crisis de la COVID-19.

Aunque los tipos de interés internacionales son bajos, no parece necesario contraer más deuda externa, ya que los gobiernos necesitan gastar más en el alivio y la recuperación de las 
economías nacionales, a menos que estas dependan fuertemente, por ejemplo, de la importación de alimentos debido a políticas anteriores que socavaron la seguridad alimentaria nacional.

- ¿Qué deberían hacer los países si les pidieran que implementaran políticas ortodoxas (o que prometan hacerlo pronto) a cambio de obtener préstamos nuevos?

-No hay una única respuesta para esta importante pregunta. En la medida en que las circunstancias lo permitan, los países en desarrollo no deberían contraer deuda externa a menos que la necesiten para importar productos esenciales como comida y medicamentos. A diferencia de lo que ocurría antes, ahora los países en desarrollo tienen más opciones en lo que refiere a prestamistas, y pueden encontrar maneras de minimizar el costo de esa deuda, ya sea interna o externa.

Además, hay diferentes maneras de contraer deuda interna soberana. Y los gobiernos deben encontrar rápida e innovadoramente nuevas opciones a bajo costo para financiar nuevos gastos basados en sus circunstancias específicas. Abrirse a nuevas ideas y opciones puede mejorar enormemente las políticas públicas en circunstancias difíciles, incluso limitadas.

-Sabemos que las IFI, como el FMI, están prestando mucho menos de lo que prometieron al inicio de la pandemia. ¿Por qué?

-No estoy en condiciones de decir qué está pasando en Washington y por qué. Sabemos que el gobierno de Trump en los Estados Unidos, que tiene poder de veto en el FMI, se opuso a una nueva emisión de derechos especiales de giro (DEG). Esto pudo haber sido percibido como un indicio de que el Directorio no está dispuesto a ofrecerles préstamos a los países en desarrollo en un momento de necesidad, tal y como había anunciado previamente su directora gerente. Su promesa y propuesta originales eran mucho mejores y más generosas que la mísera propuesta del G20, que tuvo pocos adeptos. 
El rol del G20 ante la COVID-19 en 2020 contrasta profundamente con la respuesta que le dio a la crisis financiera global una década atrás. En su punto cúlmine, en abril del 2019, el G20 recaudó 1,1 billón de dólares, que fueron en su mayoría al FMI. Los recursos adicionales del FMI se utilizaron en gran medida para hacer frente a las crisis europeas, y no a los problemas de los países en desarrollo, como se suponía que debía ser.

Las sensibilidades que atraviesan estos tiempos ya no aceptarán declaraciones públicas que ignoren descaradamente la situación de los países y las personas pobres. Sin embargo, y a todos los efectos, el esfuerzo de despliegue de la vacuna para la COVID-19 sugiere que priman los derechos de propiedad intelectual, junto con el nacionalismo de las vacunas o, más precisamente, el imperialismo que define las relaciones entre los países adinerados y su actitud hacia el resto.

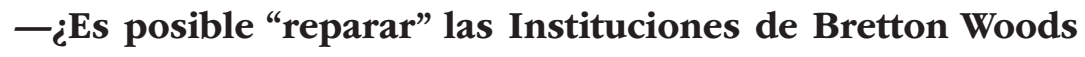
para garantizar que las políticas que recomiendan estén alineadas con las agendas de las Naciones Unidas en materia de desigualdad, cambio climático, discriminación por género y desarrollo?

-Primero, es importante reconocer que las Instituciones de Bretton Woods (IBW) han cambiado significativamente en los tres cuartos de siglo que llevan de existencia. A lo largo del tiempo, muchos fueron los factores que influenciaron estas transformaciones.

Como todos saben, la gobernanza de las IBW está dominada por los ricos. Más que "un país, un voto", o "una persona, un voto", la realidad responde mejor a la caricatura de "un dólar, un voto". Y hasta esto parece haberse congelado en el siglo XX, mucho antes de la emergencia de las economías asiáticas, particularmente de China, o incluso de India.

Pero hasta los países que producen más discursos en torno a los derechos humanos han hecho poco para avanzar en materia 
de derechos humanos sociales y económicos, sin hacer mención a lo que se conceptualiza como "derecho al desarrollo".

No cabe duda de que se habla mucho de desarrollo. Y a menudo los debates sobre la desigualdad se centran más en el género que en otras disparidades o desigualdades.

$\mathrm{Y}$, sin duda, hay una creciente preocupación por el calentamiento global, pero muchas de las iniciativas gubernamentales suponen pasarles la pelota y la factura a otros. En conclusión, aunque las inequidades y las disfuncionalidades de las IBW y del sistema existente deben ser expuestas con la esperanza y los esfuerzos puestos en una reforma, casi nadie pierde el sueño por ello. 